\title{
Shelf life evaluation of fresh-cut pineapple by using an electronic nose
}

\author{
Luisa Torri $^{\mathrm{a}, *}{ }$ Nicoletta Sinelli $^{\mathrm{b}}$, Sara Limbo $^{\mathrm{b}}$ \\ a University of Gastronomic Sciences, Piazza Vittorio Emanuele 9, 12060 Bra (CN), Italy \\ b Dipartimento di Scienze e Tecnologie Alimentari e Microbiologiche, Università degli Studi di Milano, Via Celoria 2, 20133 Milano, Italy
}

\section{A R T I C L E I N F O}

Article history:

Received 12 October 2009

Accepted 27 January 2010

We dedicate this work to the memory of Prof. Marco Riva who died unexpectedly. A valued colleague and scientist.

\section{Keywords:}

Electronic nose

Fresh-cut fruit

Freshness

Pineapple

Shelf life

Temperature

\begin{abstract}
A B S T R A C T
The aim of this work was to investigate the applicability of a commercial electronic nose in monitoring freshness of minimally processed fruit (packaged pineapple slices) during storage. The pineapple samples were taken at the beginning of their commercial life and stored at three different temperatures $\left(4-5,7-8\right.$, and $\left.15-16^{\circ} \mathrm{C}\right)$ for $6-10$ days. The measurements were performed by applying two analytical approaches using an electronic nose: a discontinuous method being a series of analyses on samples taken at various stages of storage, and a continuous method where the headspace around the fruit was automatically monitored by the electronic nose probe during the preservation of slices in a storage cell. The results obtained by the discontinuous approach showed that the electronic nose was able to discriminate between several samples and to monitor the changes in volatile compounds correlated with quality decay. The second derivative of the transition function, used to interpolate the PC1 score trend versus the storage time at each temperature, was calculated to estimate the stability time. Results revealed that fruit freshness was maintained for about 5 days at $5.3^{\circ} \mathrm{C}, 3$ days at $8.6^{\circ} \mathrm{C}$ and 1 day at $15.8^{\circ} \mathrm{C}$. Moreover, from the time-temperature tolerance chart, a $Q_{10}$ value of 4.48 was derived. These data were confirmed applying the continuous method: the fruit freshness was maintained for about 5 days at $4{ }^{\circ} \mathrm{C}, 2$ days at $7.6^{\circ} \mathrm{C}$ and 1 day at $16^{\circ} \mathrm{C}$. An interesting future development could be an application in-line of the continuous electronic nose method.
\end{abstract}

(ㄷ) 2010 Elsevier B.V. All rights reserved.

\section{Introduction}

Although minimally processed (MP) fruit and vegetables are one of the major growing segments in food retail establishments, freshcut fruit are still under study because of the difficulties in preserving their fresh-like quality over prolonged periods (Soliva-Fortuny and Martín-Belloso, 2003). The greatest hurdle to the commercial marketing is the limited shelf life, which is due to the fresh-cut processing. Manipulations such as trimming, peeling, coring, cutting and/or slicing increase respiration rates and ethylene production, and cause major tissue disruption. These physiological changes may be accompanied by cut surface discoloration, increased rate of vitamin loss, rapid softening, shrinkage, texture changes, flavour loss and off-flavour production (Toivonen and DeEll, 2002). Flavour and aroma quality are important sensory attributes for consumers and should be measured during the shelf life of MP products. However, little is known of the effects storage temperature have on volatile production and insufficient information is available about aroma profile and sensory properties of fresh-cut fruit (Beaulieu and Baldwin, 2002). The determination of the fruit and vegetable aroma profile by sensory analysis is expensive and time-consuming

\footnotetext{
* Corresponding author. Tel.: +39 0172 458509; fax: +39 0172458500.

E-mail addresses: torri.luisa@gmail.com, l.torri@unisg.it (L. Torri).
}

because it requires a selected and trained sensory panel (Lawless and Heymann, 1998). Sensory techniques provide information on overall aroma perception, olfactory thresholds and consumer acceptability, whereas instrumental analyses identify and quantify the single aroma volatile compounds. The most common instrumental techniques used to evaluate the aroma of fruit and vegetables are headspace or dynamic headspace gas chromatography coupled with mass spectrometry (GC-MS) (Wyllie, 2008), and more recently, solid-phase microextraction sampling followed by GC-MS (Pastorelli et al., 2007).

Even if these traditional methods have been successfully used for studying shelf life of fresh-cut fruit and vegetables, they are expensive, slow, require considerable analytical skill and are not suited to automation. A fast and reliable alternative method is the electronic nose. In accordance with the classical definition (Gardner and Bartlett, 1994), the electronic nose is "an instrument which comprises an array of electronic chemical sensors with partial specificity and an appropriate pattern-recognition system, capable of recognising simple or complex odours". The increasing use of the electronic nose for the evaluation of volatiles during storage is explained by several advantages: simple and fast approach, nondamaging analysis, no need for sample preparation, automatic data collection (Peris and Escuder-Gilabert, 2009). In recent years, different types of multi-sensor systems have been developed for various uses in the food industry (Shaller et al., 1998; Röck et al., 2008). 
Applications described in the literature include not only process monitoring, authenticity assessment and other food quality control studies (Peris and Escuder-Gilabert, 2009) but also food freshness evaluation and shelf-life investigation (Saevels et al., 2004; Limbo et al., 2009, 2010). The effectiveness of the e-nose in aroma evaluation of vegetables has been tested. Keshri et al. (2003) suggested the potential use of a commercial e-nose in the rapid differentiation of mycelia cultures of homobasidiomycete mushrooms. The authors reported good discriminating results between species on the basis of volatile production profiles. In the case of the work performed by De Lacy Costello et al. (2000), focussed on the early detection of soft rot in stored potato tubers, satisfactory results with prototype devices were obtained after assessing and selecting the sensors with high discriminating power. There are some practical problems involved in the development and use of an electronic nose, therefore particular attention is required. Firstly, it is necessary to eliminate changes in headspace volatile composition during sample preparation, equilibration and headspace gas sensing (sample drift). Then it is important to avoid the potential negative interaction between some "dangerous" food volatile components and sensors that could cause the poor reproducibility of e-nose sensor response data when the samples are replicated more than once (sensor drift). For instance, during the analysis of spring onions it is essential not to overwhelm the electronic nose sensors by Scontaining flavour compounds and ammonia (Abbey et al., 2005). A large number of studies have been carried out on fruit and/or their products, in particular apples, pears, apricots, peaches and oranges (Peris and Escuder-Gilabert, 2009). Nevertheless, only a very few studies have focused on fresh-cut products (Riva et al., 2001; Riva and Mannino, 2005).

The aim of this work was to investigate the application of a commercial electronic nose in the monitoring of change in the volatile compounds of a minimally processed fresh-cut pineapple during storage at different temperatures. Moreover, an innovative continuous electronic nose was compared with the classical discontinuous e-nose in order to evaluate the feasibility of this technique as a rapid and non-invasive approach for monitoring the freshness during storage of fresh-cut fruit.

\section{Materials and methods}

\subsection{Samples}

Six lots of fresh-cut pineapple slices (Ananas comosus L. cv. Golden Ripe, from Costa Rica) packaged in PVC trays sealed with a microholed film (250 g servings), supplied by the manufacturer at the beginning of their commercial life, were analyzed during storage at three different temperatures (4, 8 and $\left.16^{\circ} \mathrm{C}\right)$. Storage temperature was continuously monitored using small time-temperature recording devices (TB Econorma S.a.s., Treviso, Italy; water proof, $\pm 0.5^{\circ} \mathrm{C}$ temperature precision, diameter $=10 \mathrm{~mm}$, thickness $=4 \mathrm{~mm}$ ).

\subsection{Electronic nose}

Volatile compound emissions from samples were monitored during storage by a commercial portable electronic nose (PEN 2 model, Win Muster Airsens Analytic Inc., Schwerim, Germany). It consists of a sampling apparatus, a detector unit containing the array of sensors and pattern-recognition software (Win Muster v.16) for data recording and elaboration. The sensor array system is composed of 10 metal oxide semiconductors (MOS) of different chemical compositions and thicknesses to provide selectivity towards volatile compound classes as indicated by the instrument supplier: W1C (aromatic compounds), W5S (broad-range compounds, polar compounds, nitrogen oxides and ozone), W3C (ammonia, aromatic compounds, aldehydes, ketones), W6S (hydrogen), W5C (alkanes, aromatic compounds, less polar compounds), W1S (methane, broad-range compounds), W1W (sulphur compounds, terpenes and sulphur organic compounds), W2S (alcohols, partially aromatic compounds, ketones), W2W (aromatic compounds, sulphur organic compounds) and W3S (methane). The sensor response is expressed as resistivity $(\Omega)$. The MOS sensors rely on changes in conductivity induced by the adsorption of molecules in the gas phase and on subsequent surface reactions. They consist of a ceramic substrate coated by a metal oxide semiconducting film, and heated by a wire resistor. Due to the high operating temperatures $\left(200-500^{\circ} \mathrm{C}\right)$ the organic volatiles transferred to the surface of the sensors are totally combusted to carbon dioxide and water, leading to a change in the resistance. The use of the high temperature avoids water interference and aids rapid response and recovery times (Kohl, 1992). The detection limit of hot sensors is in the range of $1 \mathrm{ppm}$.

The electronic nose was used with two different analytical approaches: a discontinuous method and a continuous method.

\subsubsection{Discontinuous method}

For the discontinuous method (classical approach) (Limbo et al., 2009, 2010), the temperature of three samples was monitored at each storage condition. The average temperatures during storage were $5.3,8.6$ and $15.8^{\circ} \mathrm{C}$, with a standard deviation of about $0.5^{\circ} \mathrm{C}$. Samples stored at 5.3 and $8.6^{\circ} \mathrm{C}$ were analyzed after $0,1,2,3,4,5$, $6,7,8,9$ and 10 days of storage, and those stored at $16^{\circ} \mathrm{C}$ after 0,1 , 2, 3 and 6 days of storage. At each storage time and for each temperature, $13 \mathrm{~g}$ of shredded fruit were placed in $45 \mathrm{~mL}$ glass air-tight vials, hermetically sealed with a PTFE/silicone septum and a screw cap. The vials were stored at $-20^{\circ} \mathrm{C}$ until analysis. Then, the vials were equilibrated at $23 \pm 1^{\circ} \mathrm{C}$ for $90 \mathrm{~min}$ and analyzed at the same temperature in standardized conditions (Benedetti et al., 2005) The measurement device sucked the gaseous compounds from the headspace of the sample through the sensor array at $300 \mathrm{~mL} / \mathrm{min}$ for $180 \mathrm{~s}$. After sample analysis the system was purged for $400 \mathrm{~s}$ at a flow rate of $600 \mathrm{~mL} / \mathrm{min}$ with filtered air prior to the next sample injection to allow the instrument base line re-establishment. At each storage time (depending on temperature), five different samples were randomly analyzed and the average of the results was used for the statistical analysis.

\subsubsection{Continuous method}

For the continuous method (innovative approach), three samples were monitored for each temperature, resulting in average temperatures during storage at $4.0,7.6$ and $16.0^{\circ} \mathrm{C}$, with a standard deviation of about $0.5^{\circ} \mathrm{C}$.

In order to monitor continuously the volatile compounds released from the samples during storage, $100 \mathrm{~g}$ of fresh pineapple slices were placed in a suitable glass cell (volume of $500 \mathrm{~mL}$ ), equipped with an inlet (flushing air) and an outlet (sampling probe), assembled in a thermostatic incubator. The measurement device sucked the gaseous compounds from the headspace of the sample through the sensor array at $300 \mathrm{~mL} / \mathrm{min}$. Signals provided by samples stored at 4.0 and $7.6^{\circ} \mathrm{C}$ were recorded in continuous for a 10-day period, while those stored at $16.0^{\circ} \mathrm{C}$ up to 6 days.

\subsection{Statistical analyses}

The data obtained from the sensor array of the electronic nose were analyzed by principal component analysis (PCA) and cluster analysis (CA) using the XLSTAT v. 2009.4.03 (Addinsoft 1995-2009). PCA is a procedure that permits useful information to be extracted from the data, exploration of the data structure and relationships between objects and global correlation of the variables (Beebe et al. 1998). CA performs agglomerative hierarchical clustering of objects 
based on distance measures of dissimilarity or similarity. The hierarchy of clusters can be represented by a binary tree, called "a dendrogram". A final partition, i.e., the cluster assignment of each object, is obtained by cutting the tree at a specified level (Gardner and Bartlett, 1992). The data obtained by PCA were modelled by simple mathematical models using the Tablecurve 2D software $v$. 4.0 (Jandel Scientific, San Rafael, CA, USA).

\section{Results and discussion}

\subsection{Discontinuous method}

As a first step, in order to evaluate the ability of the electronic nose to discriminate among different pineapple samples, the sensor responses were elaborated by principal component analysis (PCA) according to the usual protocol for multi-sensor devices data analysis (Kent et al., 2004). PCA was performed on covariance matrix. The two first principal components, PC1 and PC2, accounted for $93 \%$ of the total variance, 77.6 and $15.7 \%$, respectively. A scatter plot for scores and factor loadings (Fig. 1), which illustrates the mutual relationships between samples and sensors, shows the sample separation according to the storage condition. Samples were distributed along PC1 and PC2 according to the storage time and storage temperature, respectively (the number beside each point represents the storage time in days). In particular, the discrimination between samples stored at the lowest temperature and the others kept at the higher temperatures is very evident. The sensors sensitive to aromatic-aliphatic compounds, aldehydes, ketones and less polar compounds (W1C, W3C and W5C) describe samples during the first days of storage. In contrast, the sensors more sensitive towards sulphur, polar and broad-range compounds, alcohols, ketones and terpenes (W1W, W1S, W2S and W5S) mainly describe the samples at the end of the storage. It would seem that the sensor array is comprised of sensors able to detect the different volatile compounds released from pineapple at different storage times. Volatile compounds cited above were reported as pineapple aroma constituents by researchers in the past (Engel et al., 1990; Umano et al., 1992; Elss et al., 2005). The ability of the electronic nose in discriminating samples as function of the storage temperature confirmed results obtained previously for fish (Limbo et al., 2009), meat (Limbo et al., 2010) and cheese (Benedetti et al., 2005).
The responses of electronic nose sensors at each temperature were also elaborated by cluster analysis (CA) (Ward and the square Euclidian distance methods) in order to investigate the similarities among pineapple samples. CA identified two main groups of samples (Fig. 2): "fresh pineapple" corresponding to 0-5 days at $5.3^{\circ} \mathrm{C}, 0-3$ days at $8.6^{\circ} \mathrm{C}$ and $0-1$ days at $15.8^{\circ} \mathrm{C}$ : "old pineapple" for the other storage conditions. Samples characterized by a weak odour were classified in the first group, likewise strongly smelling pineapple samples were assembled in the second group. In this latter group, two subgroups could be distinguished: one composed of samples stored for intermediate storage times (2 days at $15.8^{\circ} \mathrm{C}$, 4-6 days at $8.6^{\circ} \mathrm{C}$ ) and the other one composed of samples stored for the longest storage times (3-6 days at $15.8^{\circ} \mathrm{C}, 7-10$ days at $8.6^{\circ} \mathrm{C}, 6-9$ days at $5.3^{\circ} \mathrm{C}$ ). The only outlier was the sample stored at $5.3^{\circ} \mathrm{C}$ for 10 days.

CA results give the same sample distribution of PCA; in Fig. 1 "fresh pineapple" samples are located on the left side of the biplot in correspondence to the W1C, W3C, and W5C sensors, whereas "old pineapple" is located in the opposite area in the plot, influenced by the response of the other electronic nose sensors.

In order to define a pseudo stability time for freshness maintenance the trend of PC1 samples versus storage time was considered (Benedetti et al., 2005; Sinelli et al., 2005; Limbo et al., 2009, 2010). Fig. 3 shows this data modelling, i.e., the empirical transition function interpolating PC1 scores against the storage time. For each temperature, the trend of the curves seems to be characterized by a lag phase and a steep slope after it. The maximum of the second derivative of these functions allowed the measurement of the maximum time of acceptability for freshness decay, that can be considered as the "stability" time. Stability time was equal to 5.3 days at $5.3^{\circ} \mathrm{C}, 2.7$ days at $8.6^{\circ} \mathrm{C}$ and 1.2 days at $15.8^{\circ} \mathrm{C}$.

\subsection{Continuous method}

Results obtained applying the continuous method confirmed those previously provided by the classical approach. A change in many sensor signals in correspondence to the fresh aroma loss was observed. The sensor correlation matrix (data not shown) revealed that the sensors W3S, W6S and W2W were strongly correlated with the others and so contributed little to the discrimination process. In order to eliminate redundancy information (Beebe et al., 1998),

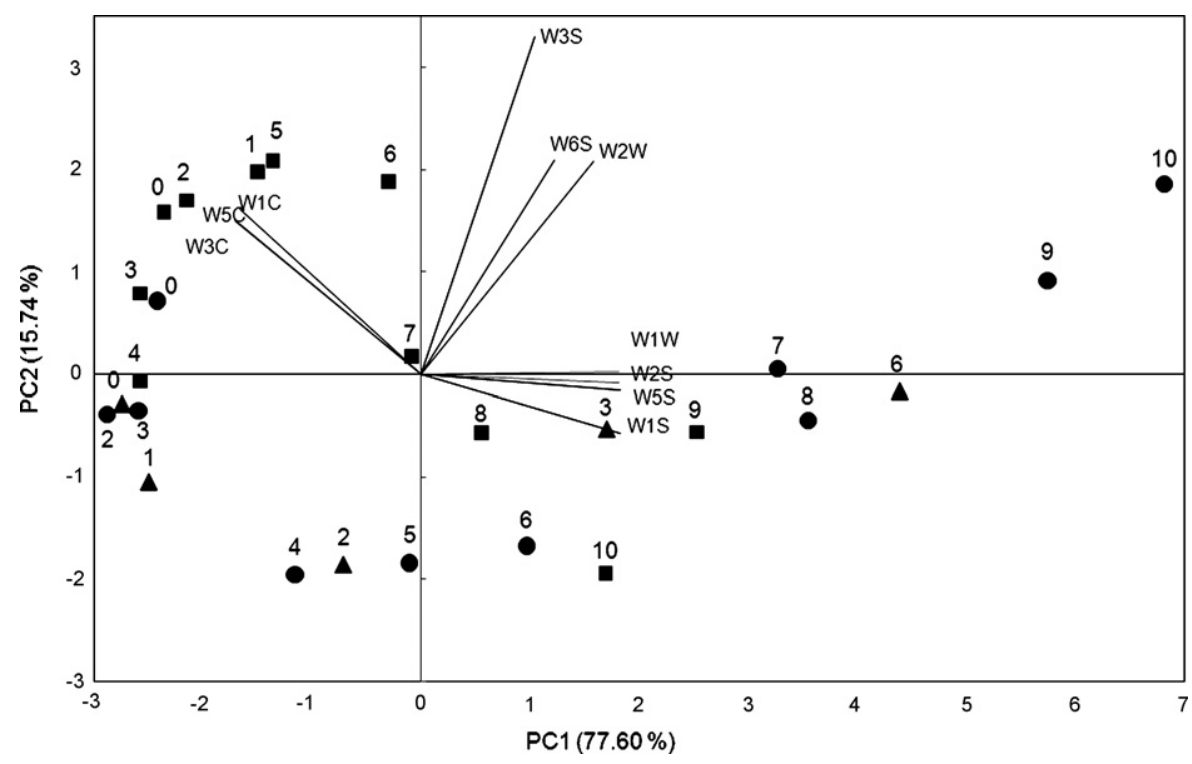

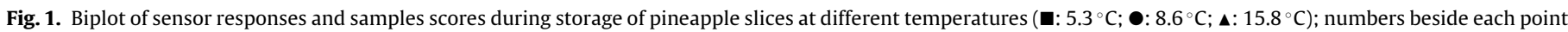
indicate the storage time in days (discontinuous approach). 


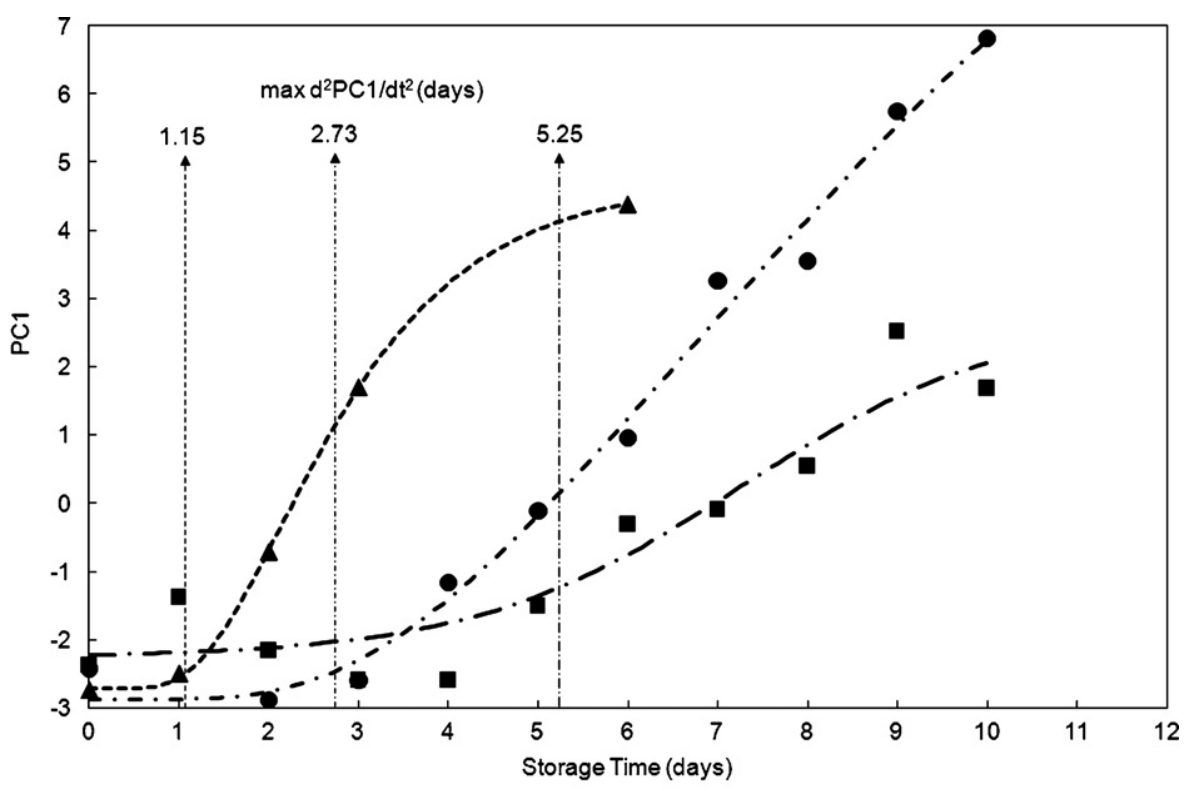

Fig. 2. PC1 score trend during storage of pineapple slices at different temperatures $\left(\boldsymbol{\square}: 5.3^{\circ} \mathrm{C} ; \bullet: 8.6^{\circ} \mathrm{C} ; \boldsymbol{\Delta}^{*}: 15.8^{\circ} \mathrm{C}\right)($ discontinuous approach).

data analysis was performed only considering the seven selected sensors (W1S, W2S, W5S, W1W, W1C, W3C and W5C) that allowed the results to be achieved satisfactorily. Fig. 3 shows, as an example, the signal change recorded by the electronic nose of pineapple samples stored at $4.0^{\circ} \mathrm{C}$. As can be seen, except for $\mathrm{W} 1 \mathrm{~W}$, the signal intensity was clearly influenced by the storage time, in good agreement with literature (Limbo et al., 2009, 2010). In particular, sensors sensitive to aromatic-aliphatic compounds, aldehydes, ketones and less polar compounds (W1C, W3C and W5C) showed a decreasing response over time to indicate a loss of the typical aroma of the fresh fruit. In contrast, the other sensors were characterized by an increasing trend. These sensors are most likely sensitive to volatile compounds related to the pineapple microflora metabolism or to the aerobic activity of the fruit product (Umano et al., 1992), and are responsible for the ethanol, ethylene and off-flavour development during storage (Spanier et al., 1998; Marrero and Kader, 2006; Montero-Calderón et al., 2008). The same qualitative trends were observed for the sample stored at 7.6 and $16.0^{\circ} \mathrm{C}$ (data not shown).

For each storage temperature, sensor responses recorded by the continuous electronic nose method have been analyzed using PCA, in order to describe the aroma changes during storage. As an example, Fig. 4 shows the results obtained by PCA applied to the sensor

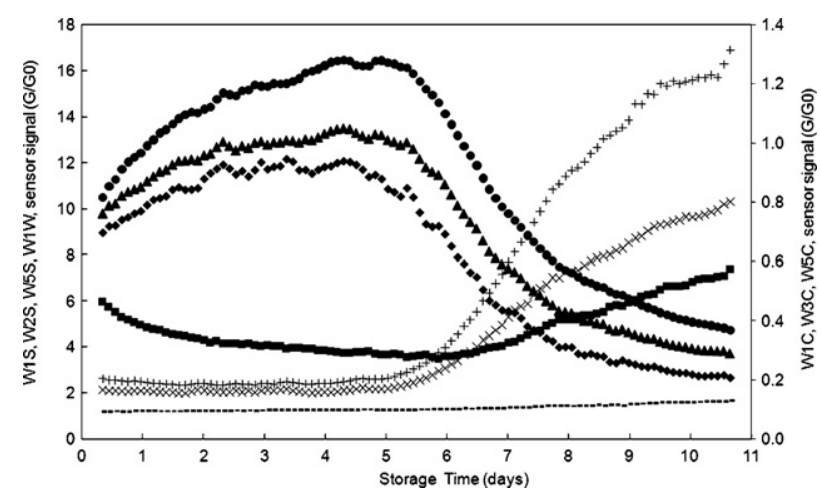

Fig. 3. Signal changes recorded by an electronic nose of pineapple samples stored at $4.0^{\circ} \mathrm{C}$ (continuous method) ( $\bullet$ W1C; $\mathbf{\wedge}$ : W3C; $\bullet$ : W5C; $\times$ : W1S; +: W2S; $\mathbf{\square}$ : W5S; -: W1W). responses of the pineapple samples stored at $4.0^{\circ} \mathrm{C}$. The first and second principal components, accounted for more than $97 \%$ of the total variance, show a distribution of the samples according to the storage time. In particular, the samples are perfectly distributed along a curve as a function of the storage time. These results, in agreement with those obtained previously with the discontinuous approach, confirmed the ability of this method to discriminate samples on the basis of the fruit freshness. Also in this case, the position of the sensors on the biplot revealed that sensors sensitive to aromatic-aliphatics compounds, aldehydes, ketones and less polar compounds (W1C, W3C and $\mathrm{W} 5 \mathrm{C}$ ) responded to the aroma profile of the fresh pineapple. The sensors sensitive towards sulphur, polar and broad-range compounds, alcohols, ketones and terpenes (W1S, $\mathrm{W} 2 \mathrm{~S}$ and $\mathrm{W} 1 \mathrm{~W}$ ) provided the highest responses when interacting with volatile compounds released from the older samples. Moreover, it is possible to notice a separation among samples along the PC1 at about 5-6 days. In particular, samples are close to each other up to 5 days as their aroma was similar; in contrast, samples older than 6 storage days are farther apart, as they were characterized by a more different odour profile.

Because PC1 explains most of the total variance (93.4\%), the PC1 scores of samples versus storage times were plotted (Fig. 5) and interpolated with an empirical transition function. The trends characterized by a lag phase followed by a steep slope were observed. The maximum of the second derivatives were extracted and considered in order to define the stability times for freshness maintenance at different temperatures (Benedetti et al., 2008; Limbo et al., 2009). The results are expressed as days of storage: $5.5,2.0$, and 1.0 at 4.0 , 7.6, and $16.0^{\circ} \mathrm{C}$, respectively.

In order to model the change of the aroma, the response of each sensor over time was normalized. The averages of normalized data were considered as "raw" index of aroma trend. For each storage temperature, clear transition kinetics were recognized (Fig. 6) and this trend was also modelled: the maximum of the second derivative function (i.e., the maximum acceleration of the normalized signal change) allowed stability time as a function of the temperature to be obtained (Benedetti et al., 2008; Limbo et al., 2010): 5.4, 2.0 , and 1.0 at $4.0,7.6$, and $16.0^{\circ} \mathrm{C}$, respectively.

Table 1 summarizes the stability times measured with two approaches, which are in good agreement. Probably, the small differences of the stability times at three storage temperatures could 


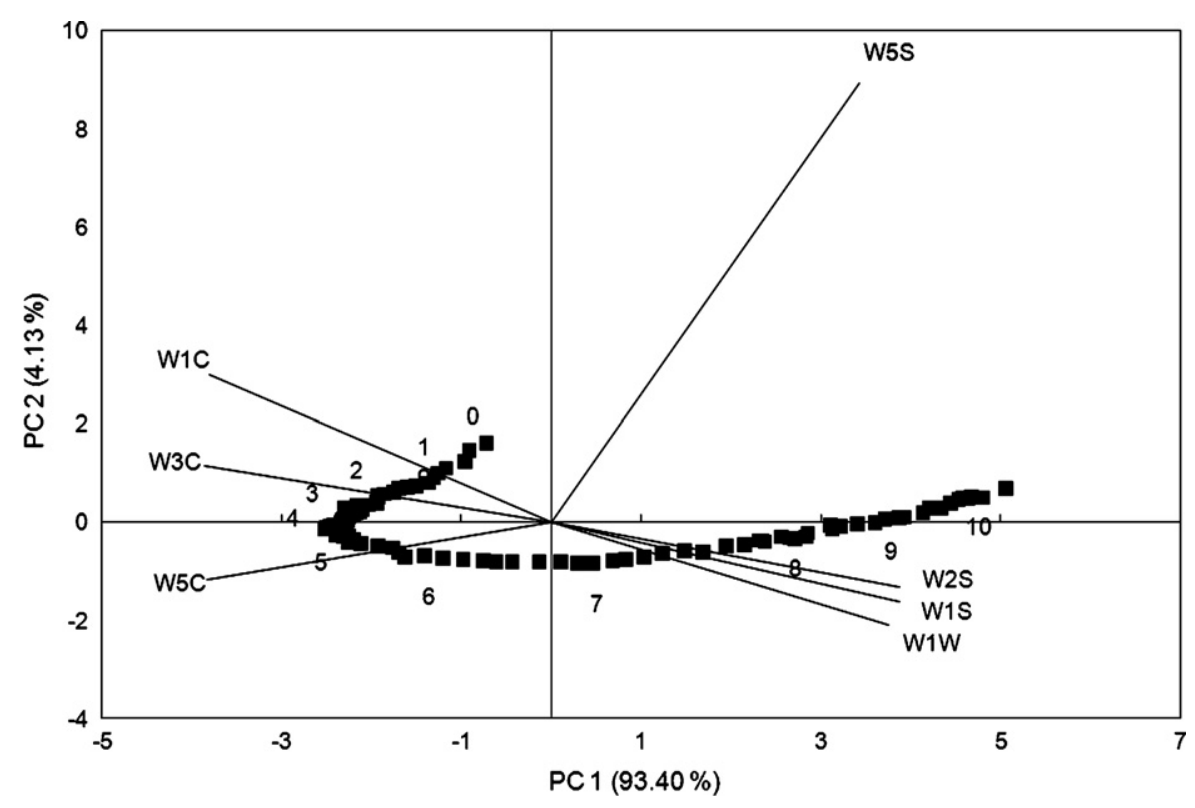

Fig. 4. Biplot of sensor responses and samples scores during storage of pineapple slices at $4.0^{\circ} \mathrm{C}$ (continuous approach).

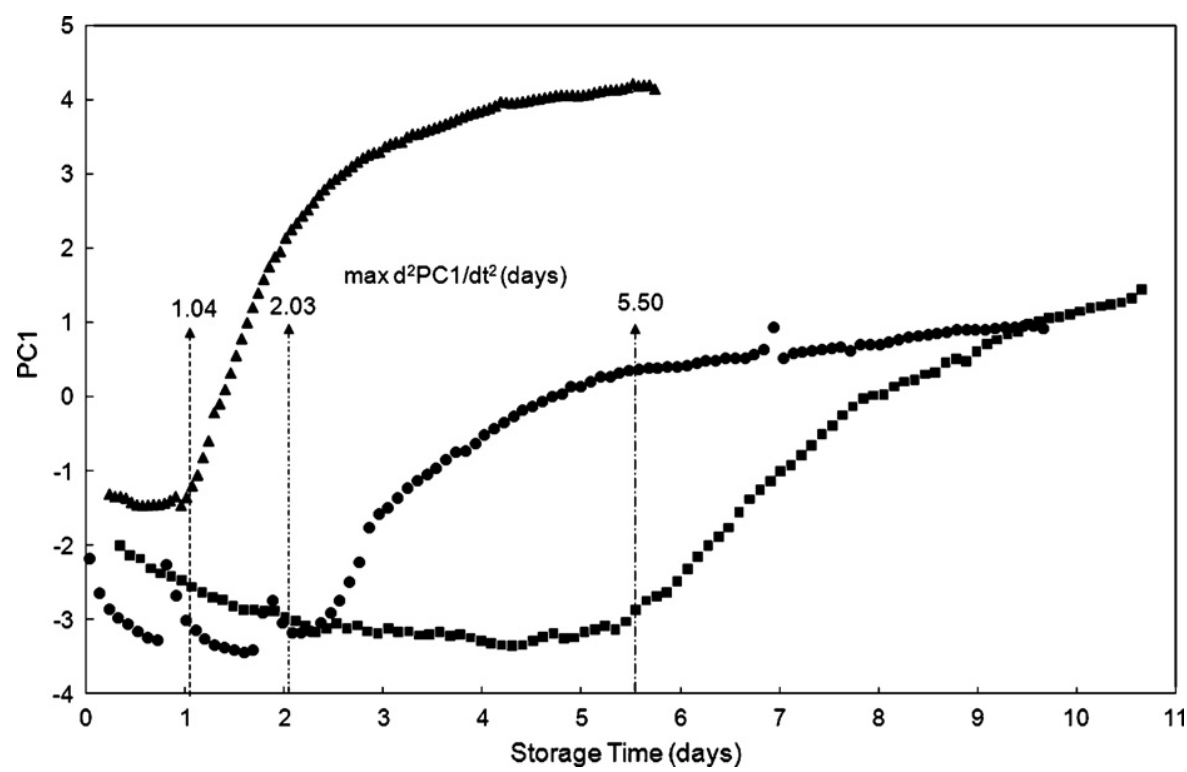

Fig. 5. PC1 score trend during storage of pineapple slices at different temperatures $\left(\boldsymbol{\square}: 4.0{ }^{\circ} \mathrm{C} ; \boldsymbol{\bullet}: 7.6^{\circ} \mathrm{C} ; \boldsymbol{\Delta}: 16.0^{\circ} \mathrm{C}\right)($ continuous approach).

be attributed to intrinsic variability of fresh fruit belonging to different lots and to storage temperatures that were not exactly the same over the two experimental steps. On the basis of these results, freshness of fresh-cut pineapple slices was maintained for

\section{Table 1}

Maximum stability times at different storage temperatures $\left({ }^{*} T_{s}\right.$ calculated from the PC1 trend; ${ }^{* *} T_{s}$ calculated from the normalized signal trend).

\begin{tabular}{|c|c|c|c|c|}
\hline \multicolumn{5}{|c|}{ Maximum stability time (days) } \\
\hline \multicolumn{2}{|c|}{ Discontinuous method } & \multicolumn{3}{|c|}{ Continuous method } \\
\hline$T\left({ }^{\circ} \mathrm{C}\right)$ & $T_{s} \mathrm{PC}^{*} *$ & $T\left({ }^{\circ} \mathrm{C}\right)$ & $T_{s} \mathrm{PC}^{*} *$ & $T_{S} \mathrm{NS}^{* *}$ \\
\hline 5.3 & 5.25 & 4.0 & 5.50 & 5.39 \\
\hline 8.6 & 2.73 & 7.6 & 2.03 & 1.99 \\
\hline 15.8 & 1.15 & 16.0 & 1.04 & 1.03 \\
\hline$Q_{10}$ & 4.10 & $Q_{10}$ & 3.60 & 3.56 \\
\hline
\end{tabular}

about 5 days at $4-5^{\circ} \mathrm{C}$ (recommended storage temperature), 2-3 days at $8^{\circ} \mathrm{C}$ (usual temperature in household refrigerators) and 1 day at $16^{\circ} \mathrm{C}$ (abuse temperature). Results confirmed that temperature is an important factor affecting pineapple post-cutting life, and that the electronic nose is a useful technique to follow the changes in aromatic profiles. Classical analytical approaches based on chemical-physical indices ( $\mathrm{pH}$, titratable acidity, colour, texture analysis, ascorbic acid content, soluble solid index, headspace gas evaluation) and microbiological data confirmed the dependence of fresh-cut pineapple shelf life on temperature. In some cases, the use of modified atmosphere packaging contributed to the freshness extension: shelf life of pineapples is about 2 weeks at very low refrigeration temperatures $\left(0-2.2^{\circ} \mathrm{C}\right)$ (Marrero and Kader, 2006), at intermediate storage temperatures $\left(4-8^{\circ} \mathrm{C}\right)$ is $8-12$ days ( $\mathrm{Gil}$ et al., 2006; Rocculi et al., 2009), at $10^{\circ} \mathrm{C}$ is 4 days and only few hours at $20^{\circ} \mathrm{C}$ (O'Hare, 1994). Comparing the results of this work with those reported by Di Egidio et al. (2009) on the pineapple fruit, there is 


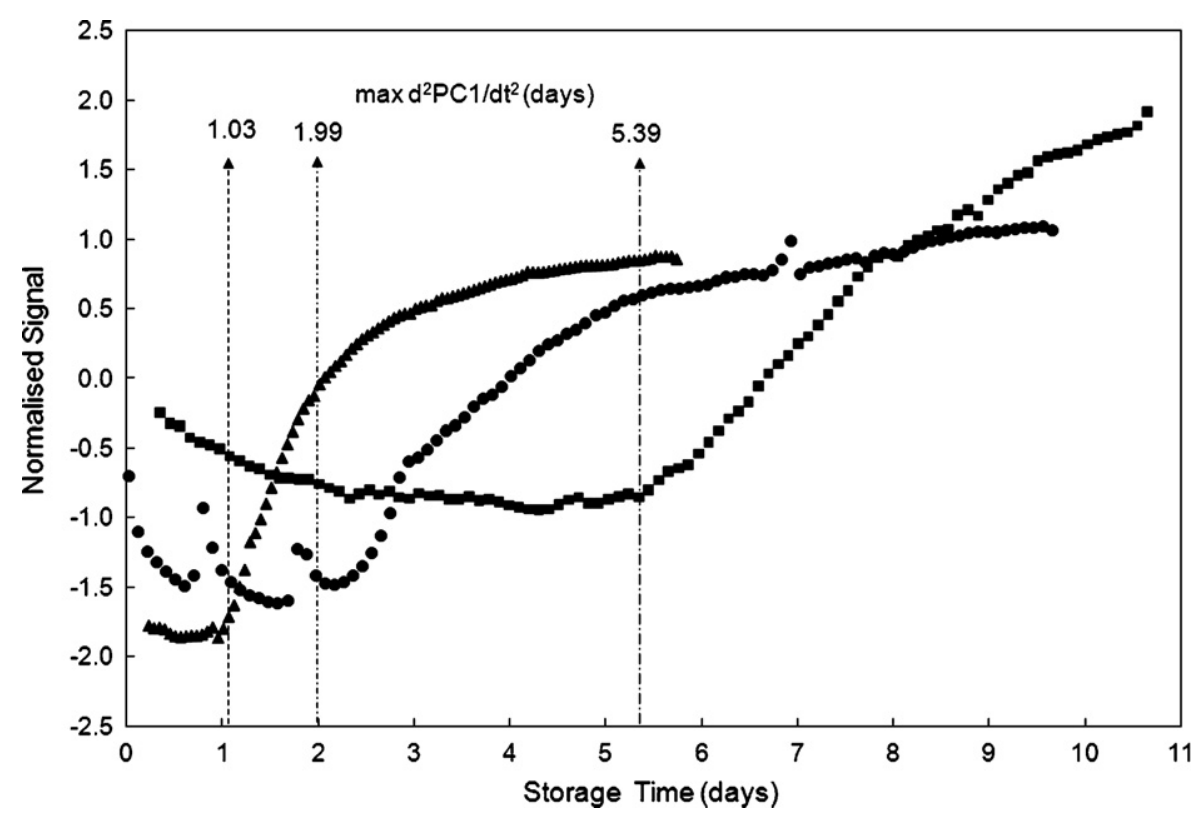

Fig. 6. Normalized signal trend and corresponding stability times at different temperatures $\left(\mathbf{\square}: 4.0^{\circ} \mathrm{C} ; \boldsymbol{\bullet}: 7.6^{\circ} \mathrm{C} ; \mathbf{\Delta}: 16.0^{\circ} \mathrm{C}\right)(\mathrm{continuous}$ approach).

a similarity in the stability times found with the electronic nose technique, NIR and MIR spectroscopy and microbiological analysis.

The knowledge of the relationship between stability time and temperature is important for the shelf life prevision during commercial distribution. Stability times can be expressed as a function of temperature in the following shelf life equation:

$t_{s}=t_{o} \exp (-b T)$

where $t_{s}$ is the stability time at temperature $T ; t_{o}$ is the stability time (or shelf life) at $0^{\circ} \mathrm{C}$ and $b$ is the slope of the regression line (Shimoni and Labuza, 2000). A time-temperature (TT) tolerance chart can be built as a practical instrument for predicting the shelf life of temperature-dependence commodities (Limbo et al., 2009). On the basis of data collected in this work, the TT tolerance chart is depicted in Fig. 7.
The graphical resolution of Eq. (1) allows the calculation of the increase in rate for a $10^{\circ} \mathrm{C}$ increase in temperature $\left(Q_{10}\right)$ from the following equation:

$Q_{10}=\exp (10 b)$

In Table 1 , the relevant $Q_{10}$ values are also reported, indicating the effect of temperature on loss of quality of the fresh-cut pineapple. The $Q_{10}$ index indicates the $n$-fold decrease of the shelf life for a $10^{\circ} \mathrm{C}$ temperature increase (Labuza, 1982). The values are in good accordance, so a $Q_{10}$ average value of $3.8 \pm 0.3$ was calculated.

The results confirm the effectiveness of the e-nose in giving back a fingerprint of pineapple freshness. In particular the continuous method could be an interesting application in-line process using an e-nose probe placed directly in the storage environment. In this case, it is possible to characterize fruit flavours and monitor the

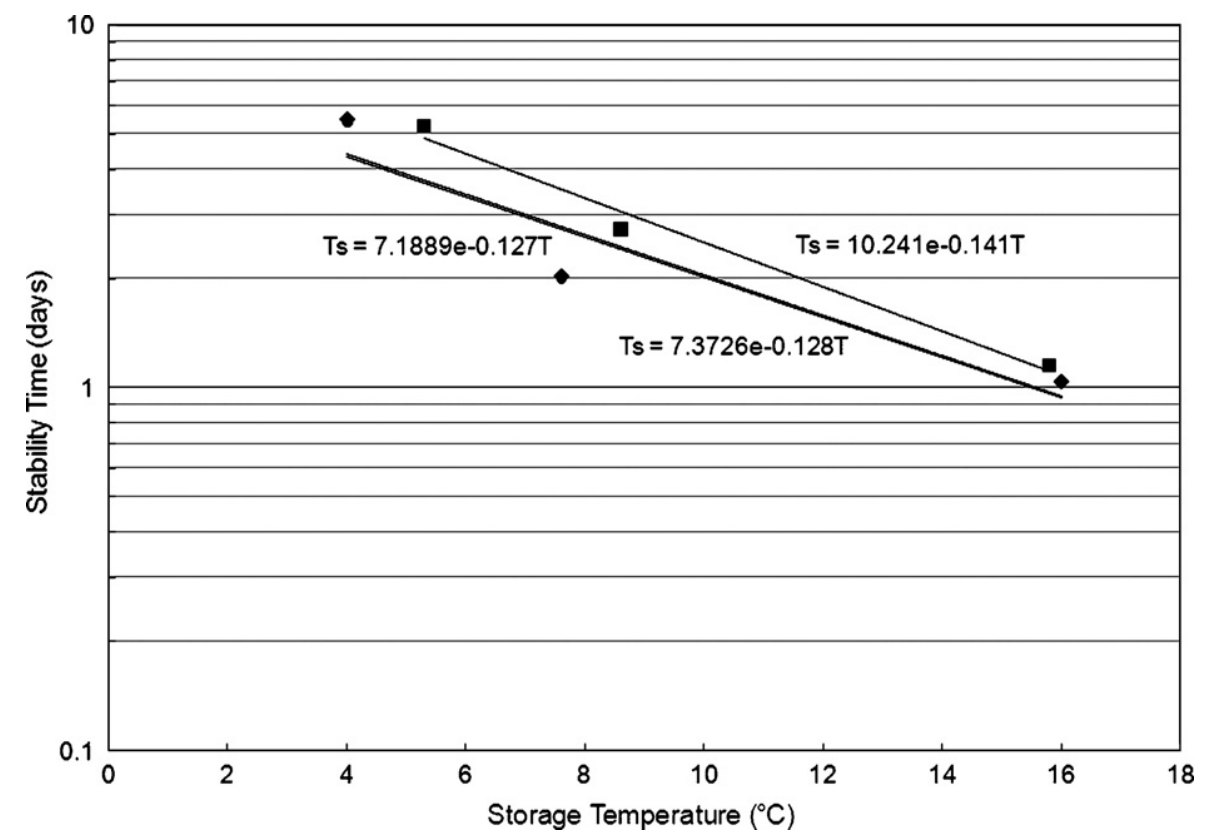

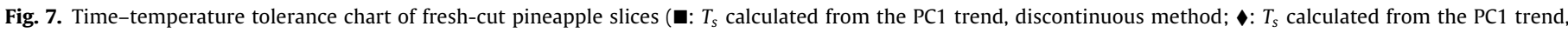
continuous method; $\bullet: T_{s}$ calculated from the normalized signal trend, continuous method). 
change of volatile compounds under commercial conditions using an automated technique.

\section{Conclusions}

The electronic nose enables the complex changes of the aroma profile to be monitored, as demonstrated in this work. The results showed the effectiveness of a commercial electronic nose in the modelling of the aroma change of the fresh-cut pineapple as a function of storage time and temperature. The obtained $Q_{10}$ values confirmed that fresh-cut pineapple is a very perishable and delicate fruit and storage temperature plays a critical role in quality maintenance. The approach used in this study can be applied to evaluate the loss of aroma quality of other fresh-cut products, in which enzymatic and microbiological processes are responsible for freshness loss with a negative influence on the aroma and flavour quality during storage. The good agreement among results provided by the classical and continues approaches, suggests that an interesting future development could be the use of a electronic nose in-line by means of a probe placed in the storage environment. Then it would be possible to check the ripening stage of fruit and vegetables and to monitor the change of volatile compounds during storage under commercial conditions. In this case, an electronic nose could be an interesting quality control tool for industry, especially for distributors.

\section{References}

Abbey, L., Joyce, D.C., Aked, J.B., Smith, B., 2005. Evaluation of eight spring onion genotypes, sulphur nutrition and soil-type effects with an electronic nose. J. Hort. Sci. Biotechnol. 80, 375-381.

Beaulieu, J.C., Baldwin, E.A., 2002. Flavor and aroma of fresh-cut fruit and vegetables. In: Lamikanra, O.(Ed.), Fresh-cut Fruits and Vegetables: Science, Technology, and Market. CRC Press, Boca Raton, pp. 391-425.

Beebe, K.R., Pell, R.J., Seasholtz, M.B., 1998. Chemometrics: A Practical Guide. John Wiley and Sons, New York.

Benedetti, S., Sinelli, N., Buratti, S., Riva, M., 2005. Shelf life of crescenza cheese as measured by electronic nose. J. Dairy Sci. 88, 3044-3051.

Benedetti, S., Buratti, S., Spinardi, A., Mannino, S., Mignani, I., 2008. Electronic nose as a non-destructive tool to characterise peach cultivars and to monitor their ripening stage during shelf-life. Postharvest Biol. Technol. 47, 181-188.

De Lacy Costello, B.P.J., Ewen, R.J., Gunson, H.E., Ratcliffe, N.M., Spencer-Phillips, P.T.N., 2000. The development of a sensor system for the early detection of soft rot in stored potato tubers. Meas. Sci. Technol. 11, 1685-1691.

Di Egidio, V., Sinelli, N., Limbo, S., Torri, L., Franzetti, L., Casiraghi, E., 2009. Evaluation of shelf-life of fresh-cut pineapple using FT-NIR and FT-IR spectroscopy. Postharvest Biol. Technol. 54, 87-92.

Elss, S., Preston, C., Hertzig, C., Heckel, F., Richling, E., Schreier, P., 2005. Aroma profiles of pineapple fruit (Ananas comosus [L.] Merr.) and pineapple products. Lebensm. Wiss. Technol. 38, 263-274.

Engel, K.H., Heidlas, J., Tressl, R., 1990. The flavour of tropical fruits (banana, melon, pineapple). In: Morton, I.D., Macleod, A.J. (Eds.), Food Flavours. Part C, The Flavours of Fruits. Elsevier, Amsterdam, pp. 195-220.

Gardner, J.W., Bartlett, P.N., 1992. Pattern recognition in odour sensing. In: Gardner, J.W., Bartlett, P.N. (Eds.), Sensors and Sensory Systems for an Electronic Nose. Kluwer Academic Publishers, Boston, pp. 161-179.

Gardner, J.W., Bartlett, P.N., 1994. A brief history of electronic noses. Sens. Actuators B 461 (18), 211-220.

Gil, M.I., Aguayo, E., Kader, A.A., 2006. Quality changes and nutrient retention in fresh-cut versus whole fruits during storage. J. Agric. Food Chem. 54, 4284-4296.
Kent, M., Oehlenschlager, J., Mierke-Klemeyer, S., Manthey-Karl, M., Knochel, R., Daschner, F., 2004. A new multivariate approach to the problem of fish quality estimation. Food Chem. 87, 531-535.

Keshri, G., Challen, M., Elliott, T., Magan, N., 2003. Differentiation of Agaricus species and other homobasidiomycetes based on volatile production patterns using an electronic nose system. Mycol. Res. 107, 609-613.

Kohl, D., 1992. Fundamentals and recent developments of homogeneous semiconducting sensors. In: Gardner, J.W., Bartlett, P.N. (Eds.), Sensors and Sensory Systems for an Electronic Nose. Kluwer Academic Publishers, Dordrecht, pp. 53-76.

Labuza, T.P., 1982. Scientific evaluation of shelf life. In: Labuza, T.P. (Ed.), Shelf Life Dating of Foods. Food Nutr. Press, Westport, pp. 41-44

Lawless, H.T., Heymann, H., 1998. Sensory Evaluation of Foods: Principles and Practices, 1 ed. Chapman \& Hall, New York.

Limbo, S., Sinelli, N., Torri, L., Riva, M., 2009. Freshness decay and shelf life predictive modelling of European sea bass (Dicentrarchus labrax) applying chemical methods and electronic nose. Lebensm. Wiss. Technol. 42, 977-984.

Limbo, S., Torri, L., Sinelli, N., Franzetti, L., Casiraghi, E., 2010. Evaluation and predictive modeling of shelf life of minced beef stored in high-oxygen modified atmosphere packaging at different temperatures. Meat Sci. 84, 129-136.

Marrero, A., Kader, A.A., 2006. Optimal temperature and modified atmosphere for keeping quality for fresh-cut pineapples. Postharvest Biol. Technol. 39, 163-168

Montero-Calderón, M., Rojas-Graü, M.A., Martín-Belloso, O., 2008. Effect of packaging conditions on quality and shelf-life of fresh-cut pineapple (Ananas comosus). Postharvest Biol. Technol. 50, 182-189.

O'Hare, T.J., 1994. Respiratory Characteristics of Cut Pineapple Tissue. Posthrvest Group, DPI, Queensland, Australia, 1994 Report.

Pastorelli, S., Torri, L., Valzacchi, S., Rodriguez, A., Limbo, S., Simoneau, C., 2007. SPME and sensors as a rapid method for the determination of hexanal in nuts. Food Addit. Contam. 11, 1219-1225.

Peris, M., Escuder-Gilabert, L., 2009. A 21st century technique for food control: electronic noses. Anal. Chim. Acta 638, 1-15.

Riva, M., Franzetti, L., Galli, A., 2001. Effect of storage temperature on microbiological quality and shelf-life of ready to use salads. Ann. Microbiol. 51, 39-52.

Riva, M., Mannino, S., 2005. Shelf-life monitoring and modelling by e-nose and image-analysis. Ital. Food Beverage Technol. 42, 11-19.

Rocculi, P., Cocci, E., Romani, S., Dacchetti, G., Dalla Rosa, M., 2009. Effect of 1MCP treatment and $\mathrm{N}_{2} \mathrm{O}$ MAP on physiological and quality changes of fresh-cut pineapple. Postharvest Biol. Technol. 51, 371-377.

Röck, F., Barsan, N., Weimar, U., 2008. Electronic nose: current status and future trends. Chem. Rev. 108, 705-725.

Saevels, S., Lammertyna, J., Berna, A.Z., Veraverbeke, E.A., Di Natale, C., Nicolai, B.M., 2004. An electronic nose and a mass spectrometry-based electronic nose for assessing apple quality during shelf life. Postharvest Biol. Technol. 31, 9-19.

Shaller, E., Bosset, J.O., Escher, F., 1998. Electronic nose and their application to food Lebensm. Wiss. Technol. 31, 305-316.

Shimoni, E., Labuza, T.P., 2000. Modeling pathogen growth in meat products: future challenges. Trends Food Sci. Technol. 11, 394-402.

Sinelli, N., Barzaghi, S., Giardina, C., Cattaneo, T.M.P., 2005. Use of the FT-NIR spectroscopy to monitor the shelf-life of packed industrial Ricotta cheese. J. Near Infrared Spectrosc. 13, 293-300.

Soliva-Fortuny, R.C., Martín-Belloso, O., 2003. New advances in extending the shelflife of fresh-cut fruits: a review. Trends Food Sci. Technol. 14, 341-353.

Spanier, A.M., Flores, M., James, C., Lasater, J., Lloyd, S., Miller, J.A., 1998. Fresh-cut pineapple (Ananas sp.) flavor. Effect of storage. In: Contis, E.T., Ho, C.T., Mussinan, C.J., Parliament, T.H., Shahidi, F., Spanier, A.M. (Eds.), Developments in Food Science. Food Flavors: Formation, Analysis, and Packaging Influences. Elsevier, Amsterdam, pp. 331-343.

Toivonen, P.M.A., DeEll, J.R., 2002. Physiology of fresh-cut fruits and vegetables. In: Lamikanra, O. (Ed.), Fresh-cut Fruits and Vegetables: Science, Technology, and Market. CRC Press, Boca Raton, pp. 91-124.

Umano, K., Hagi, Y., Nakahara, K., Shoji, A., Shibamoto, T., 1992. Volatile constituents of green and ripened pineapple (Ananas comosus [L.] Merr.). J. Agric. Food Chem. 40, 599-603.

Wyllie, S.G., 2008. Flavour quality of fruit and vegetables: are we on the brink of major advances? In: Brückner, B., Wyllie, S.G. (Eds.), Fruit and Vegetable Flavour: recent Advances and Future Prospects. CRC Press, Boca Raton. 